\title{
Knowledge and practice on solar ultraviolet radiation and its impact on vision: a case study among Kenyan optometrists
}

\author{
Shadrack Muma (1) \\ Department of Public Health, Maseno University, Maseno, Kenya
}

\begin{abstract}
BACKGROUND: The purpose of the study was to investigate optometrist's knowledge and practice on solar ultraviolet radiation and its implication on vision.

MATERIAL AND METHOD: A survey was conducted using purposive sampling. The study was conducted from January 2020 to February 2020 using emailed questionnaires. Basic socio-demographic characteristics, participants' knowledge and practice on solar ultraviolet radiation were assessed. The key variables under consideration were knowledge and practice on solar ultraviolet radiation. Odds ratios were calculated and chi-square test conducted. RESULTS: A total of 270 optometrists received the survey with a response rate of $81 \%$ and mean age of $26.4 \pm 4.3$ years. Only $36 \%$ had good knowledge of the effects produced by solar radiation. On attenuation knowledge only $1 \%$ recommended contrast filters, $13 \%$ polarizing lenses and $4 \%$ polycarbonate. There solar ultraviolet radiation and cortical cataract $(\mathrm{p}=0.012)$ was significantly different. Men had good knowledge about cataract $(\mathrm{OR}=1.63,95 \%$ $\mathrm{CI}=1.56-1.76)$, keratopathy $(\mathrm{OR}=1.72,95 \% \mathrm{CI}=1.35-1.56)$, and pterygium $(\mathrm{OR}=1.36,95 \% \mathrm{CI}=1.32-1.43)$. Most respondents 66\% could only dispense Photochromatic lenses because they are readily available.

CONCLUSION: The study denotes that solar ultraviolet radiation is an issue of global public health concern. Awareness is still a challenge and optometrists are well placed to create awareness. Public health act should initiate a policy on the attenuation of solar ultraviolet radiation.
\end{abstract}

KEY WORDS: solar; ultraviolet; radiation; optometrists; knowledge; practice

Ophthalmol J 2020; Vol. 5, 136-142

\section{INTRODUCTION}

Exposure to solar ultraviolet radiation has been shown to have significant public health implication. Overexposure is associated with various pathologies to the human eye. According to the World Health Organization, 20\% of the global blindness is attributed to solar ultraviolet radiation [1]. Globally, overexposure to solar ultraviolet radiation has caused approximately 1.5 million disability adjusted life year and premature deaths totaling to 60,000 [2]. In the United Kingdom, it is estimated that over 14.5 million workers are exposed to solar ultraviolet radiation [1]. In sub-Saharan Africa, data on solar ultraviolet radiation is limited. However, cataract being one of the greatest burdens resulting from overexposure to solar ultraviolet radiation is at $14 \%$ of the global disease burden [3]. In Kenya, data on solar ultraviolet radiation does not exist, however, cataract is the leading cause of blindness. It contributes to $43 \%$ of the Kenyan blindness [4]. Therefore; knowledge of optometrists on solar ultraviolet radiation is sig- 
nificant as they are well placed to create awareness to the public.

The total burden of disease caused by cataract globally is estimated at $25 \%$ and it is due to cortical cataract [2]. The ultraviolet radiation does not penetrate, however, it highly affects the human eye since the eye is sensitive to wavelength of 555 nanometer [5]. Absorbing the solar ultraviolet radiation produces photo luminescent and photo chemical effects to the crystalline lens. Based on occupation, at some point in time, one will have to be exposed to solar ultraviolet radiation. The magnitude of solar ultraviolet radiation to the eye depends on the time of exposure and the concentration. The effects produced by solar ultraviolet radiation to the eye include; pinguecula, pterygium, cortical cataract, keratopathy, photokeratitis and age related macular degeneration [3]. These are key ocular conditions which can only be understood by optometrists and ophthalmologists. In the African context, the chief complaint reported by patients is photophobia. A study in South Africa, among optometrists on the major complains raised by patient, $97 \%$ mentioned photophobia [6]. A similar high proportion was recorded in Nigeria where $89 \%$ complained of photophobia. While on functional low vision due to pterygium, 5000 per million were affected [7]. In Tanzania, a survey showed that there was a link between cortical cataract and solar ultraviolet radiation 33\% [8]. This suggests that most exposed individuals seek advice from optometrists and other eye care providers. In Kenya, in as much as data on solar ultraviolet is not available, knowledge of optometrists on the same has not been assessed.

In as much as solar ultraviolet radiation is significant to public health, it is a great risk factor to other ocular conditions. Globally, the majority of citizens do outdoor jobs with only a few involved in indoor jobs. This is a clear indication that the general population is exposed to solar ultraviolet radiation. A study in South Africa showed that 78\% of the working population does outdoor jobs with only $29 \%$ involved in indoor jobs [9]. Attenuation of solar ultraviolet radiation can only be achieved by using reflective lenses such as tinted lenses. A study conducted in the United States showed that $64 \%$ of the patients who had cortical cataract were involved in outdoor activities for a long period of time. ${ }^{7}$ In sub Saharan Africa, studies on optometrists involvement in attenuation of solar ultraviolet radiation has not been well articulated [10]. However other countries such as South Africa and Nigeria have started developing strategies to curb solar ultraviolet radiation. In Kenya, attenuation on solar ultraviolet radiation is not known and optometrists are well placed to look at the issue. However, knowledge of Kenyan optometrists on the attenuation of solar ultraviolet radiation is not known.

Wearing gears for protection against solar ultraviolet radiation is very vital. To maximize awareness, optometrists practice is deemed necessary to the general public. A study in Australia reported that $67 \%$ of the interviewed optometrists were advising patients the management of solar ultraviolet radiation [3]. However, in Nigeria, only $2 \%$ of the optometrists could advise the patients on the effects of solar ultraviolet radiation [11]. This shows that developed countries are becoming more aware of solar ultraviolet radiation effects and the optometrists are playing a crucial role. The general population constitutes the literate and the illiterate, therefore public awareness on solar ultraviolet radiation is significant. In Kenya, little is known on solar ultraviolet radiation and no evidence of practice among optometrists exists. Therefore this study assessed the knowledge and practice on solar ultraviolet radiation.

\section{MATERIAL AND METHODS}

The questionnaires were given to optometrists practising all over Kenya. A quantitative approach was adopted in which questions were administered through their emails. The population of Kenya is estimated at 47 million with 47 counties. Primary eye care providers are distributed all over the counties with the majority based in Nairobi County. Only respondents who returned the consent were included in the study. The respondents were able to withdraw at anytime. An ethical approval was sought from Maseno University ethics review committee.

Recruitment was done from January 2020 to February 2020. A response rate of $81 \%$ was attained. The study adopted a purposive sampling (Fig. 1). The questionnaire had been pre-tested during a pilot to assess for Cronbach's reliability (assessed at the level of 0.974 and 0.926 for knowledge and practice questionnaire respectively) and validity (assessed by performing a Pearson correlation coefficient and obtained $0.000<0.05, \mathrm{n}=30$ ). Participants who participated in the pilot study were excluded. Statistical Package for Social Sciences version 17 software was used to analyze the data. Values of $\mathrm{p}<0.05$ were considered statistically significant. 


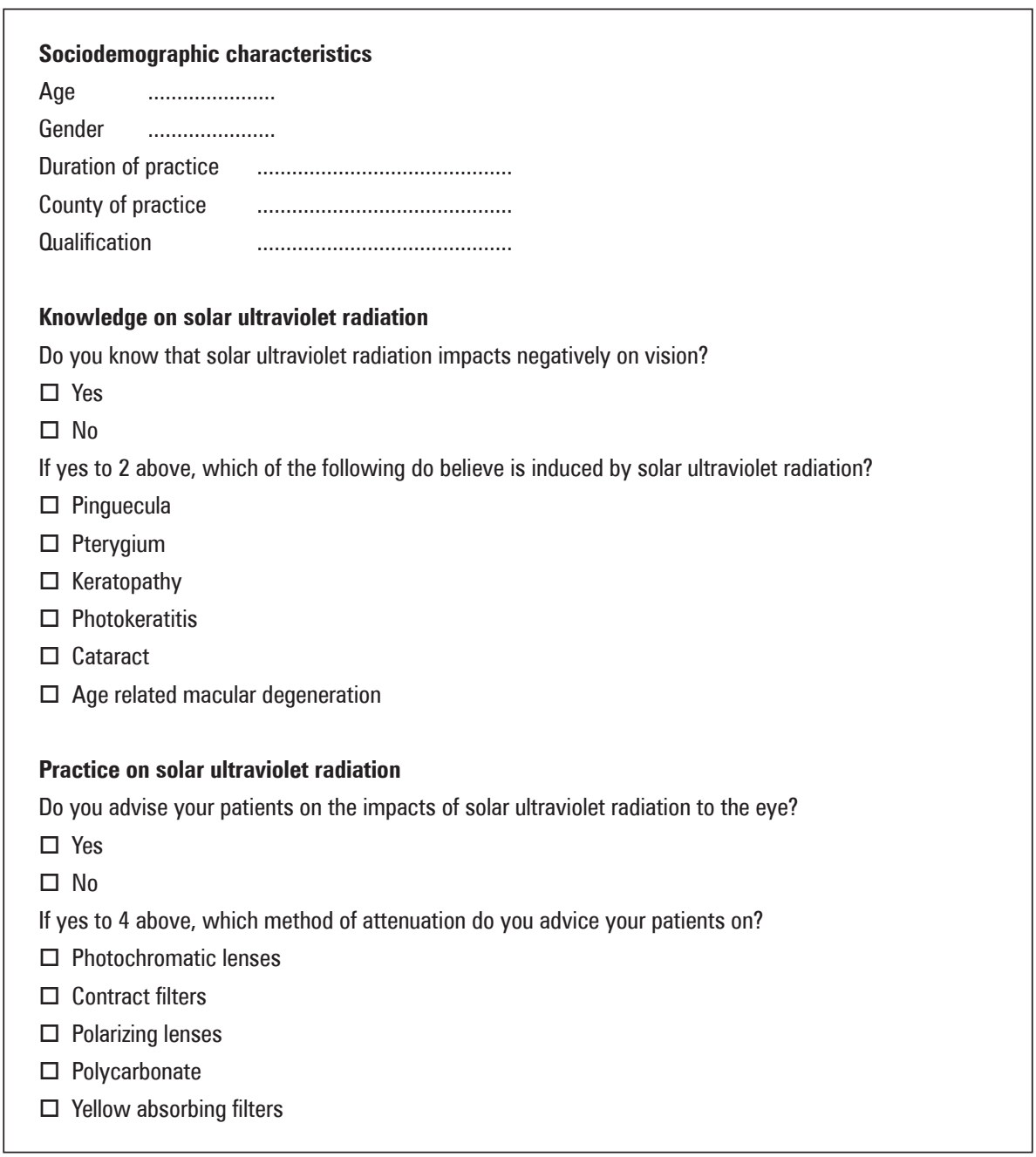

FIGURE 1. The survey questionnaire

\section{RESULTS \\ KNOWLEDGE OF SOLAR ULTRAVIOLET RADIATION}

Most respondents $64 \%$ were not aware of the effects of solar ultraviolet radiation. However, less than half of the respondents (36\%) knew the effects produced by solar ultraviolet radiation. Only $7 \%$ of the respondents could identify photochemical effects. A slightly higher proportion (72\%) could identify the time of exposure as a factor responsible for solar ultraviolet radiation magnitude to the eye. Majority of the respondents (78\%) had a good knowledge on cataract. However, knowledge of pterygium $24 \%$, keratopathy $16 \%$, pinguecula $21 \%$, photokeratitis $12 \%$ and age-related macular degeneration $10 \%$ were significantly low. There was a statistically significant difference on solar ultraviolet radiation and cortical cataract $(\mathrm{p}=0.012)$. Compared with women, men had good knowledge about cataract
$(\mathrm{OR}=1.63,95 \% \mathrm{CI}=1.56-1.76)$, keratopathy $(\mathrm{OR}=1.72,95 \% \mathrm{CI}=1.35-1.56)$, and pterygium $(\mathrm{OR}=1.36,95 \% \mathrm{CI}=1.32-1.43)$ as conditions arising from exposure to solar radiation (Tab. 1).

\section{KNOWLEDGE ON THE ATTENUATION OF SOLAR ULTRAVIOLET RADIATION}

Majority of the respondents $63 \%$ agreed that sunlight is useful to the human body. Over three quarter of the respondents $87 \%$ were dispensing Photochromatic lenses. Other attenuation methods dispensation was significantly low. For example only $1 \%$ recommended contrast filters, $6 \%$ yellow absorbing filters, $13 \%$ polarizing lenses and $4 \%$ polycarbonate. Majority of the respondents 3\% who recommended polycarbonate were based in Nairobi. Polycarbonate were 2.5 (95\% $\mathrm{CI}=2.1-3.5)$ times more likely to protect the eye from solar ultraviolet radiation than Photochromatic lenses. Compared with younger respondents 
Table 1.Knowledge on solar ultraviolet radiation

\begin{tabular}{|l|c|}
\hline Variable & Number (\%) \\
\hline Do you know the effects produced by solar radiation? \\
\hline Yes & 36 \\
\hline No & 64 \\
\hline Which solar radiation induced eye effect do you know? \\
\hline Pinguecula & 21 \\
\hline Pterygium & 24 \\
\hline Keratopathy & 16 \\
\hline Cortical cataract & 78 \\
\hline Photokeratitis & 12 \\
\hline Age-related macular degeneration & 10 \\
\hline
\end{tabular}

(25-30 years old), elderly individuals had less knowledge on contrast filters (35-40 years old: $\mathrm{OR}=0.40$, $95 \% \mathrm{CI}=0.39-0.67 ; \geq 40$ years old: $\mathrm{OR}=0.61$, $95 \% \mathrm{CI}=0.13-0.48)$, yellow absorbing $(35-40$ years old: $\mathrm{OR}=0.57,95 \% \mathrm{CI}=0.37-0.59 ; \geq 40$ years old: $\mathrm{OR}=0.53,95 \% \mathrm{CI}=0.25-0.41)$, and polarizing lenses $(35-40$ years old: $\mathrm{OR}=0.89,95 \%$ $\mathrm{CI}=0.64-0.76 ; \geq 40$ years old, $\mathrm{OR}=0.41,95 \%$ $\mathrm{CI}=0.41-0.60)$ as attenuation means for solar ultraviolet radiation.

\section{PRACTICE ON SOLAR ULTRAVIOLET RADIATION}

A relatively low proportion of the respondents $48 \%$ were advising patients on solar ultraviolet radiation. Majority of the respondents $78 \%$ were not concerned about solar ultraviolet radiation but refractive error correction. Most respondents 66\% could only dispense Photochromatic lenses because they are readily available. The age-specific analysis found that middle-aged individuals $(30-35$ years

\section{Table 2. Practice on solar ultraviolet radiation}

\begin{tabular}{|l|c|}
\hline Variable & Number (\%) \\
\hline Do you advice your patients on solar radiation? \\
\hline Yes & 48 \\
\hline No & 52 \\
\hline Which methods of attenuation do you practice? \\
\hline Photochromatic lenses & 78 \\
\hline Contrast filters & 1 \\
\hline Polarizing lenses & 13 \\
\hline Polycarbonate & 3 \\
\hline Yellow absorbing filters & 6 \\
\hline
\end{tabular}

old) were significantly less likely to identify the contribution of solar ultraviolet radiation $(\mathrm{OR}=0.31$, $95 \% \mathrm{CI}=0.13-0.45$ ) to ocular pathologies (Tab. 2).

\section{ASSOCIATION BETWEEN DEMOGRAPHIC CHARACTERISTICS AND KNOWLEDGE ON SOLAR RADIATION}

Association between demographic characteristics and knowledge on solar radiation has been presented on Table 3.

\section{DISCUSSION}

The present study investigated optometrist knowledge and practice on solar ultraviolet radiation in Kenya. Solar ultraviolet radiation has been shown to produce side effect such as photochemical and photoluminscent effects. In this study the knowledge of optometrists was low. However, this could be attributed to the lack of policy guidelines on solar radiation by the ministry of health. A study

\begin{tabular}{|c|c|c|c|c|}
\hline \multirow{2}{*}{ Variable } & \multicolumn{2}{|c|}{ Knowledge } & \multirow{2}{*}{ OR (95\% CI) } & \multirow{2}{*}{ p value } \\
\hline & Good & Poor & & \\
\hline \multicolumn{5}{|c|}{ Age group $(n=219)$} \\
\hline $25-30$ & $24(56 \%)$ & $4(24 \%)$ & $12.0(3.0-13.6)$ & $<0.155$ \\
\hline $35-40$ & $7(30 \%)$ & $14(70 \%)$ & 1.0 & \\
\hline \multicolumn{5}{|c|}{ Duration of practice } \\
\hline$<5$ & $19(6.0 \%$ & $6(25.0 \%)$ & 1.0 & \\
\hline $6-9$ & $3(1.0 \%)$ & $5(20.8 \%)$ & $0.2(0.0-0.3)$ & 0.033 \\
\hline$>10$ & $3(2.0 \%)$ & $13(54.2 \%)$ & $0.1(0.0-0.3)$ & $<0.001$ \\
\hline \multicolumn{5}{|l|}{ Qualification } \\
\hline BSc Optometry & $25(14 \%)$ & $7(50 \%)$ & $2.5(0.5-9.2)$ & 0.145 \\
\hline Dip Optometry & $10(8.6 \%)$ & $7(80 \%)$ & 1.0 & \\
\hline
\end{tabular}


conducted in the United States to investigate effects produced by solar radiation showed that $78 \%$ of the general population ware aware of the side effects [14]. This is relatively a greater proportion attributed to well establish policy to handle solar ultraviolet radiation. At the same time, awareness could have been established by the optometrists. However, there is no data on the knowledge of optometrists on solar radiation in the United States. In the African context, South Africa reported $60 \%$ of the general population being aware of solar radiation [15]. Being that South Africa comprises, both whites and blacks, the knowledge on radiation could have been improved as whites are at greater risk. In the Kenyan context, policy guidelines regulating solar ultraviolet radiation do not exist. Therefore, optometrists are well placed to create awareness. However their knowledge on solar ultraviolet radiation is significantly low. Being that policy does not exist, the optometrists ought to have taken the initiative to create public awareness on solar radiation effects to the eye.

Globally, everyone is exposed to solar ultraviolet radiation. However, with its adverse effects on the human eye, preventive measures should be adopted and applied. In Kenya, less than $50 \%$ are engaged in indoor jobs [16]. This is a clear indication that the majority are exposed to solar ultraviolet radiation. This study has reported a low level of knowledge on attenuation techniques. In Australia, a study conducted among optometrists on solar ultraviolet radiation showed that $76 \%$ were aware of the attenuation methods [17]. A similar scenario was reported among optometrists in the United Kingdom, where $75 \%$ of the optometrists were aware of the attenuation method [18]. This is seen in developed countries as policies inclined towards solar ultraviolet radiation are well established. In as much as optometrists are well placed to create awareness on the attenuation methods for solar radiation, African context data still misses. In Nigeria, 34\% of the general population ware aware of the attenuation methods [14]. However, optometrist's knowledge has not been established. This could be due to lack of policies on solar ultraviolet radiation. In Kenya, nothing has been documented on attenuation awareness by the general public and the optometrist knowledge on solar radiation. In the literature search, little exist on knowledge of optometrists on solar ultraviolet radiation. Therefore this study will be the first in Africa to report knowledge of optometrists on solar ultraviolet radiation.
Prolonged exposure to solar ultraviolet radiation is a risk factor for cataract. A study in Australia reported no significant association between solar ultraviolet radiation and pinguecula, pterygium and keratopathy $(\mathrm{p}=0.67)$ [19]. However, there was a significant association between solar ultraviolet radiation and cortical cataract $(\mathrm{p}=0.002)$. The study results are concurrent to our study in which there was a significant association between cortical cataract and solar radiation $(\mathrm{p}=0.014)$. This is a great risk to blindness as cataract contributes to Kenyan blindness by 43\% [4]. In this study, most optometrists did not have the knowledge of cortical cataract as attributed to solar ultraviolet radiation. In Nigeria, most optometrists $65 \%$ are aware of cortical cataract to be attributed to solar radiation [7]. In general, optometrists need to engage in a more comprehensive diagnosis and proper history taking to ascertain the causes of the ocular conditions. Based on literature such, this will be the first study relating optometrists and solar ultraviolet radiation. The World Health Organization recommends certain measures to apply in curbing solar radiation. A study in Tanzania showed that $90 \%$ of the most affected by solar radiation are people with albinism [12]. Other studies reported that whites are more prone to skin diseases attributed to solar radiation than blacks. In Kenya, albinism exists however, little is known on solar ultraviolet radiation effects to the eye. The optometrists are well placed to assess this and come up with conclusive information. Therefore, a global investigation of optometrist's knowledge needs to be established so as to reduce the incidences of solar ultraviolet radiation effects.

Acquiring a filter to curb solar ultraviolet radiation goes at a cost. This may influence the optometrist's scope of advice as they may pre judge a patient. In the United States, filters to curb solar radiation are affordable while in Kenya only Photochromatic lenses are affordable. A study conducted in Tanzania showed that $22 \%$ were wearing absorbing filters against solar ultraviolet radiation [11]. This was the contrary in Kenya where 60\% wear photochromatic lenses for fashion purposes [4]. Most optometrists based in Mombasa Kenya reported that $45 \%$ wear sunglasses due to the hot conditions. Due to climate change, in Canada, it was reported that $90 \%$ wear filters during hot seasons [20].In as much this happens globally, little is known on the practice of optometrist on solar ultraviolet radiation. Attention on attenua- 
tion and practice on solar radiation is significant, however, it is the responsibility of optometrists to facilitate this.

The study had certain limitation. Firstly other eye care providers were not included in the survey. Therefore the results of the study may not be generalized to other eye care providers. Secondly, other stakeholders were not included in the survey and this influenced the government to take and stand on solar ultraviolet radiation.

The strength of the present study was it first investigated the personnel who see the general population. Involving optometrists in the study was a baseline in first getting whether the exports understand the situation before moving to the general population.

\section{CONCLUSION}

Solar ultraviolet radiation exists. Therefore there is need of public health policy on solar radiation to provide disease burden associated with overexposure and in exposure. There is need for solar radiation protection programmes to raise awareness of the health hazards. A global solar radiation index should be integrated so as to enhance a long term public health protection approach. A global investigation of optometrist's knowledge and practice on solar ultraviolet radiation should be determined. This will ensure that continuous update to the general population on solar radiation reaches the general public.

\section{Ethics approval}

Ethical approval was obtained from the institution review board of Maseno University. Participation was voluntary, and the respondents could withdraw from the survey at any time during the study period. The responses were kept confidential, and the data were de-identified before data analysis. The study adhered to the tenets of the Declaration of Helsinki.

\section{Consent for publication}

N.A.

\section{Availability of data and materials}

The dataset is available from corresponding author.

\section{Competing interests}

No competing interest.

\section{Funding}

No funding received.

\section{Author contribution}

S.M developed the proposal and conducted the study.

\section{Acknowledgement}

Thanks to participants.

\section{REFERENCES}

1. Bishop KD, Olszewski AJ. Epidemiology and survival outcomes of ocular and mucosal melanomas: a population-based analysis. Int $\mathrm{J}$ Cancer. 2014; 134(12): 2961-2971, doi: 10.1002/ijc.28625, indexed in Pubmed: 24272143.

2. Brandberg Y, Sjödén PO, Rosdahl I. Assessment of sun-related behaviour in individuals with dysplastic naevus syndrome: a comparison between diary recordings and questionnaire responses. Melanoma Res. 1997; 7(4): 347-351, doi: 10.1097/00008390-199708000-00011, indexed in Pubmed: 9293486.

3. Moise AF, Gies HP, Harrison SL. Estimation of the annual solar UVR exposure dose of infants and small children in tropical Queensland, Australia. Photochem Photobiol. 1999; 69(4): 457-463, indexed in Pubmed: 10212577.

4. Rosmini F, Stazi MA, Milton RC, et al. Italian-American Cataract Study. Group A dose-response effect between a sunlight index and age-related cataracts. Ann Epidemiol. 1994; 4(4): 266-270, doi: 10.1016/1047-2797(94)90081-7, indexed in Pubmed: 7921315 .

5. Luande J, Henschke Cl, Mohammed N. The Tanzanian human albino skin. Natural history. Cancer. 1985; 55(8): $1823-$ 1828, doi: 10.1002/1097-0142(19850415)55:8<1823::aidcncr2820550830 > 3.0.c0;2-x, indexed in Pubmed: 3978567.

6. Raasch BA, Buettner PG. Multiple non-melanoma skin cancer in an exposed Australian population. Int J Dermatol. 2002; 41(10): 652-658, doi: 10.1046/j.1365-4362.2002.01573.x, indexed in Pubmed: 12390187.

7. Parisi AV, Kimlin MG. Comparison of the spectral biologically effective solar ultraviolet in adjacent tree shade and sun. Phys Med Biol. 1999; 44(8): 2071-2080, doi: 10.1088/0031-9155/44/8/316, indexed in Pubmed: 10473215.

8. Hersey P, Bradley M, Hasic E, et al. Immunological effects of solarium exposure. Lancet. 1983; 1(8324): 545-548, doi: 10.1016/s01406736(83)92808-8, indexed in Pubmed: 6131254.

9. McCarty CA. Epidemiology of pterygium in Victoria, Australia. Br J Ophthalmol. 2000; 84(3): 289-292, doi: 10.1136/bjo.84.3.289, indexed in Pubmed: 10684840.

10. Norn M. Spheroid degeneration, keratopathy, pinguecula, and pterygium in Japan (Kyoto). Acta Ophthalmol. 1984; 62(1): 54-60, doi: 10.1111/j.1755-3768.1984.tb06756.x, indexed in Pubmed: 6720277.

11. Nwosu SN. Ocular problems of young adults in rural Nigeria. International Ophthalmology. 1998; 22(5): 259-263, doi: 10.1023/a:1006338013075, indexed in Pubmed: 10826540.

12. Panchapakesan J, Hourihan J, Mitchell P. Prevalence of pterygium and pinguecula: the Blue Mountains Eye Study. Aust N Z J Ophthalmol. 1998; 26(Suppl 1): S2-S5, doi: 10.1111/j.1442-9071.1998.tb01362.x, indexed in Pubmed: 9685008.

13. Rasanayagam RT. The incidence and racial distribution of pterygium in West Malaysia. Trans Ophthalmol Soc NZ. 1973; 25: 56-59, indexed in Pubmed: 4519231.

14. Sasaki H, Asano K, Kojima M, et al. [Epidemiological Survey of Ocular Diseases in K Island, Amami Islands Prevalence of Cataract and Ptery- 
gium]. Nippon Ganka Gakkai Zasshi. 1999; 103(7): 556-563, indexed in Pubmed: 10443131

15. Sebban A, Hirst LW. Pterygium recurrence rate at the Princess Alexandra Hospital. Aust NZJ Ophthalmol. 1991; 19(3): 203-206, doi: 10.1111/j.1442-9071.1991.tb00661.x, indexed in Pubmed: 1958364.

16. Singh MM, Murthy GV, Venkatraman R. A study of ocular morbidity among elderly population in a rural area of central India. Indian J Ophthalmol. 1997; 45(1): 61-65, indexed in Pubmed: 9475015.

17. Duncan DD, Muñoz B, Bandeen-Roche $K$, et al. Assessment of ocular exposure to ultraviolet-B for population studies. Salisbury Eye Evaluation Project Team. Photochem Photobiol. 1997; 66(5):
701-709, doi: 10.1111/j.1751-1097.1997.tb03210.x, indexed in Pubmed: 9383994.

18. Garssen J, Nowal M, Loveren HV. UV-B induced immunomodulation: a health risk. Polar Research. 2017; 18(2): 339-343, doi: 10.3402/ polar.v18i2.6593.

19. Moise AF, Gies HP, Harrison SL. Estimation of the Annual Solar UVR Exposure Dose of Infants and Small Children in Tropical Queensland, Australia. Photochem Photobiol. 1999; 69(4): 457-463, doi: 10.1111/ j.1751-1097.1999.tb03312.x, indexed in Pubmed: 10212577.

20. Parisi AV, Kimlin MG. Comparison of the spectral biologically effective solar ultraviolet in adjacent tree shade and sun. Phys Med Biol. 1999; 44(8): 2071-2080, doi: 10.1088/0031-9155/44/8/316, indexed in Pubmed: 10473215. 